\title{
PROPERTIES AND BIOLOGICAL BEHAVIOUR OF COOMASSIE BLUE*
}

BY

\author{
S. H. TAYLOR + AND J. M. THORP
}

From the Department of Medicine, Postgraduate Medical School, London, and Imperial Chemical Industries Pharmaceuticals Division, Alderley Park, Macclesfield, Cheshire

Received November 29, 1958

The demonstration by Hamilton et al. (1948) and Wërko et al. (1949) that the analysis of timeconcentration curves of intravenously injected Evans Blue (T-1824) gave estimates of the cardiac output in man that corresponded closely with those obtained by the direct Fick method stimulated a widespread use of the dye method. However, those properties of Evans Blue that led Dawson et al. (1920) to select it from some 60 dyes as a plasma volume indicator, in particular its affinity for protein and the persistence of tissue coloration, detract from its value in studies of the circulation, especially if repetition of observations is required. Alternative indicators have been widely sought, but none can yet be regarded as wholly satisfactory. In a new attempt to find a solution to the problem the distribution and fate in vivo of some 50 compounds were examined in preliminary animal experiments. As a result the dye, Coomassie Blue, was selected for more detailed examination, the results of which are here reported.

\section{Constitution and Properties of Coomassie Blue}

Coomassie Blue is a dye of the formula:

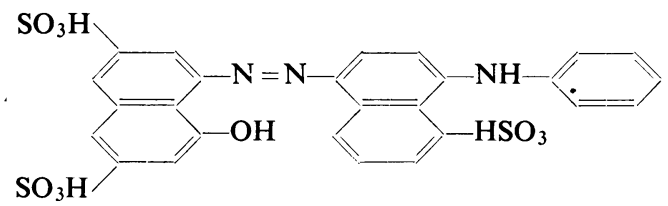

In the form of its sodium salt, it is readily soluble in water and solutions are stable on storage and may be sterilized by autoclaving. The purification process applied to the dye used for these experiments gives a chromatographically pure and homogeneous product. The light absorption maximum of Coomassie Blue in aqueous solution occurs at 565-570 $\mathrm{m} \mu$, the maximum being shifted to 580 $590 \mathrm{~m} \mu$ in the presence of plasma $\left(\mathrm{E}_{1 \mathrm{~cm} .}^{1 \%}\right.$ about 600$)$. The absorption of light by aqueous solutions and mixtures of the dye with plasma is linearly proportional to the concentration of dye present in each.

Coomassie Blue may be extracted from plasma and tissues by the urea and acetone method of Clausen and Lifson (1956): this permits its accurate determination without interference by hæmolysis or lipæmia. Details of the extraction method are outlined in a later publication (Taylor and Shillingford, 1959). The absorption spectra of Coomassie Blue before and after extraction from the plasma are shown in Fig. 1. In the final acetone extract the dye shows an absorption maximum at $585 \mathrm{~m} \mu$, with an increase of absorbance of 15 per cent, as compared with aqueous solutions. Recovery of the dye from plasma by this extraction method is $95-100$ per cent, and light absorption

* U.K. Patent Specification No. 798443. "Coomassie" is a registered Trade Mark of Imperial Chemical Industries

$\dagger$ Medical Research Fellow in Clinical Research. Limited. 
of the extract is linearly proportional to dye concentration when solutions are measured in a spectrophotometer such as the Unicam SP 600 . The absorption spectra of extracts of the dye from the plasma of animals, at intervals up to two hours after injection, are identical with that of the original dye.

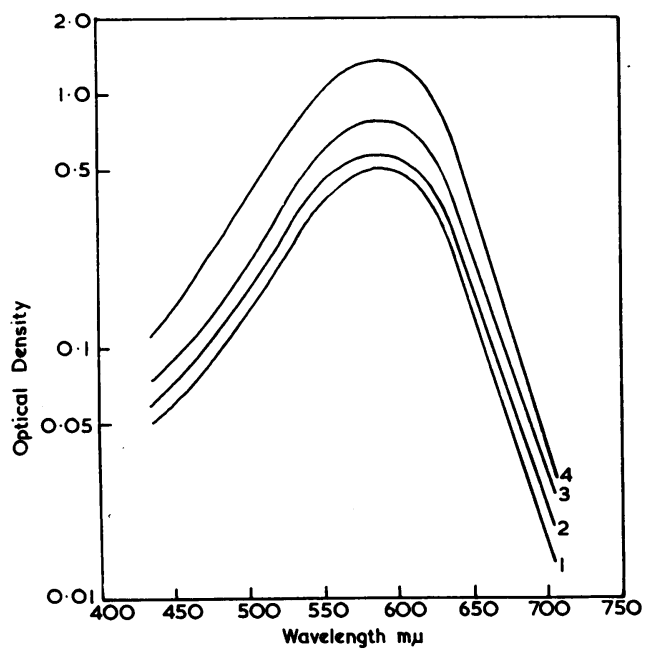

FIG. 1.-Absorption spectra of Coomassie Blue.

1.-Acetone extract of plasma 45 mins. after injection into rat.

2.-Dye in acetone $(0.5 \mathrm{mg} . / 100 \mathrm{ml}$.).

3.-Acetone extract of dye after addition to plasma in vivo.

4.-Acetone extract of plasma 15 mins. after injection into rat.

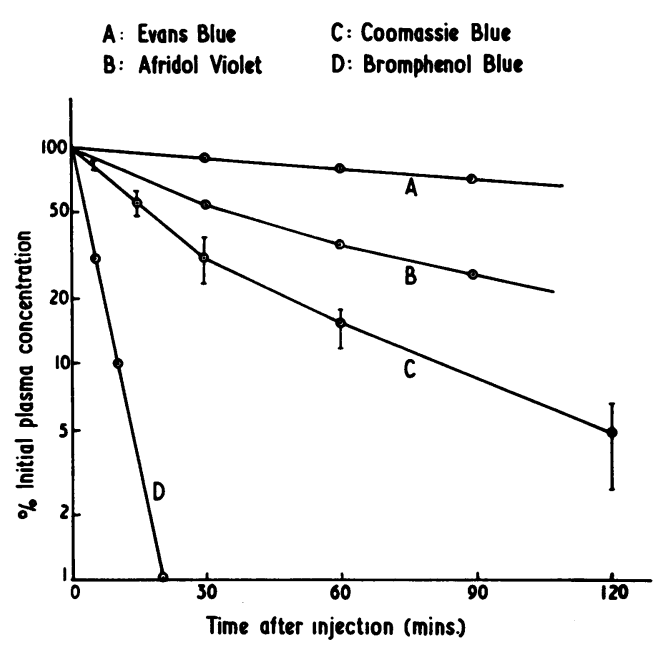

FIG. 2.-Clearance of dyes from the plasma of rabbits following intravenous administration of $5 \mathrm{mg}$. $/ \mathrm{kg}$. body weight. The points and bars on curve $\mathrm{C}$ show the mean and range of values found in four rabbits (weights $2 \cdot 5-3 \cdot 5 \mathrm{~kg}$.).

Coomassie Blue at concentrations up to $10 \mathrm{mg} . / 100 \mathrm{ml}$. is virtually completely $(>98 \%)$ bound to the serum proteins or to 4 per cent aqueous bovine albumin solution, as determined by dialysis. On electrophoresis of serum containing Coomassie Blue, the dye is found to migrate with the albumin fraction.

\section{Distribution, Metabolism, and Excretion of Coomassie Blue}

The apparent volume of distribution and rate of clearance from plasma of Coomassie Blue and other dyes were determined by injecting $5 \mathrm{mg}$. per $\mathrm{kg}$. body weight of the dye intravenously into rabbits and taking samples of blood for analysis of dye content at timed intervals from five minutes to two hours thereafter. Extrapolation of the dye concentrations to zero time enabled the apparent volumes of distribution of the dyes to be calculated. These are shown, together with the half life (time for concentration of dye to drop by one half after injection) in Table I. (The dye Indigo Carmine proposed for circulatory studies by Lacy et al. (1955) is included as an example of a rapidly cleared indicator.) The volumes of distribution and relative rates of clearance of these dyes were found to be substantially the same in further experiments in both the cat and the dog.

As shown in Fig. 2, Afridol Violet and Coomassie Blue are more rapidly cleared than Evans Blue. Further study of Afridol Violet revealed that, after parenteral administration, it gave rise to persistent skin pigmentation. Coomassie Blue, however, caused no skin pigmentation, but merely a transient blueing due to its presence in the peripheral circulation.

An experimental demonstration that the surface coloration following injection of Coomassie Blue is due to its presence in the peripheral circulation and not to tissue staining, as occurs with Evans Blue, is shown in Fig. 3. Shortly after intravenous injection of the dye, rats were 
TABLE I

Distribution and Clearance of Dyes after Intravenous ADMINISTRATION OF 5 MG./KG. BODY WEIGHT to RABBITS

\begin{tabular}{ll|c|c}
\hline \multicolumn{1}{c|}{ Dye } & $\begin{array}{c}\text { Apparent volume of } \\
\text { distribution } \\
\text { (\% body weight) }\end{array}$ & $\begin{array}{c}\text { Half life of } \\
\text { dye in plasma } \\
\text { (minutes) }\end{array}$ \\
\hline Evans Blue .. &. & $3 \cdot 8-6 \cdot 3$ & $>120$ \\
Afridol Violet &. & $4 \cdot 6-5 \cdot 0$ & $30-40$ \\
Coomassie Blue &.. & $4 \cdot 5-5 \cdot 6$ & $15-20$ \\
Indigo Carmine &.. & $(10)^{*}$ & $<3$ \\
Bromphenol Blue &. & $(10)^{*}$ & $<3$ \\
\hline
\end{tabular}

* The clearance of these dyes was too rapid to allow accurate determination of their volume of distribution.

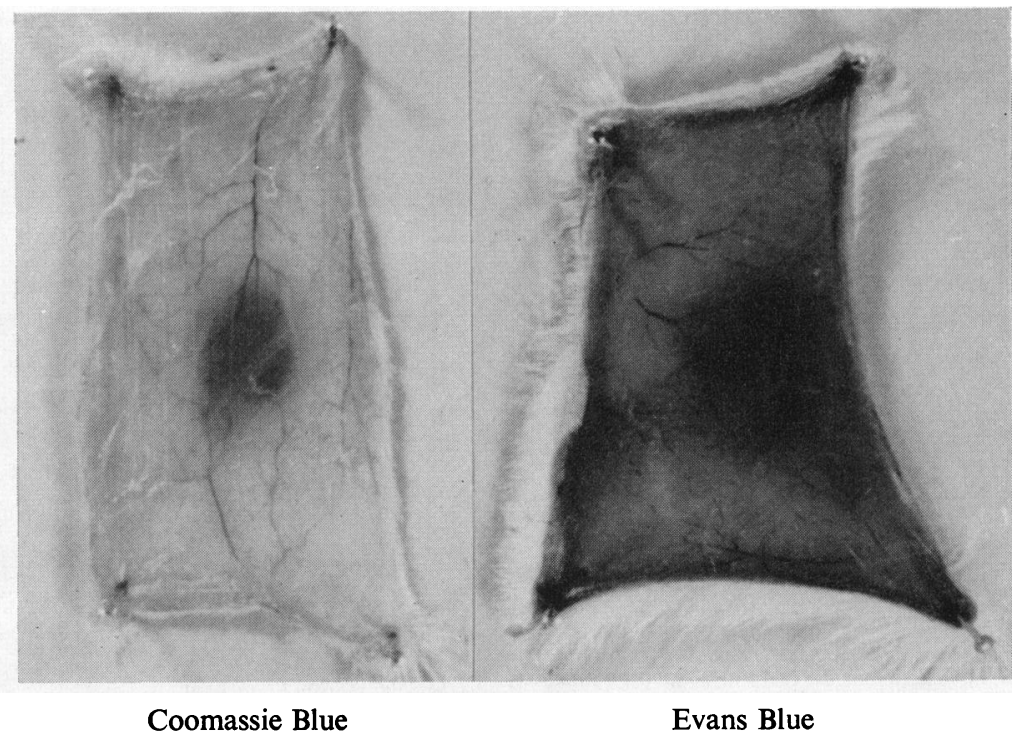

Fig. 3.-Comparison of the diffusion of circulating Evans Blue and Coomassie Blue at an area of increased capillary permeability induced by intradermal peptone injection. Rat skin $\left(\times \frac{3}{4}\right)$.

injected intradermally with $0.1 \mathrm{ml} .2$ per cent peptone solution, and the injection site excised 30 minutes thereafter. The local increase in capillary permeability caused by the peptone results in diffusion of the dye from the circulation into the surrounding tissue. The degree of contrast in colour provides a readily discernible measure of the initial tissue pigmentation due to the dye. Whereas pre-administration of Evans Blue resulted in the blue bleb being scarcely distinguishable in colour from that of the deeply stained surrounding tissue, in the case of Coomassie Blue the surrounding tissue was quite unstained and contrasted sharply with the area of dye that had diffused around the injection site.

Coomassie Blue is metabolized by reductive fission of the azo link, as has been described for other azo derivatives (Fouts et al., 1957). After fission, the two components of the molecule are mainly excreted in the urine, partly as such, and partly as further metabolic derivatives. Less than 3 per cent of the injected dye is excreted unchanged in the urine after the administration of large doses. A considerable concentration of the dye occurs in the bile, and, though a small fraction of its metabolites are present in the fæces, little unchanged dye is found. 


\section{ToXICITY}

Coomassie Blue is significantly less toxic than Evans Blue, being well tolerated at single doses of $500 \mathrm{mg} . / \mathrm{kg}$. body weight intraperitoneally in the mouse, whereas Evans Blue causes delayed deaths in all mice at doses of $200 \mathrm{mg} . / \mathrm{kg}$. body weight. In the mouse the $\mathrm{LD}_{50}$ of Coomassie Blue given intravenously was found to be $450 \mathrm{mg} . / \mathrm{kg}$. body weight, about 100 times the dose used for human indicator dilution studies. Repeated intravenous injections of $10-30 \mathrm{mg}$. $/ \mathrm{kg}$. body weight of the dye in both the rat and the rabbit caused no detectable macroscopic or microscopic lesions of any tissue. Of rats that received $15 \mathrm{mg}$. Coomassie Blue subcutaneously fortnightly for six months, none showed any evidence of local or generalized carcinogenic or other activity when studied over a period of two years. Intravenous doses of $5-10 \mathrm{mg} . / \mathrm{kg}$. body weight of Coomassie Blue in the dog and cat caused no alteration of respiration, blood pressure, pulse rate, or electrocardiogram.

\section{Cardiac Output Measurement}

A limited comparison of Coomassie Blue with Evans Blue as a cardiac output indicator in the dog showed the dye to give valid results (Fig. 4), as was to be expected from its method of selection. These results have since been confirmed by more detailed studies in man (Taylor and Shillingford 1959).

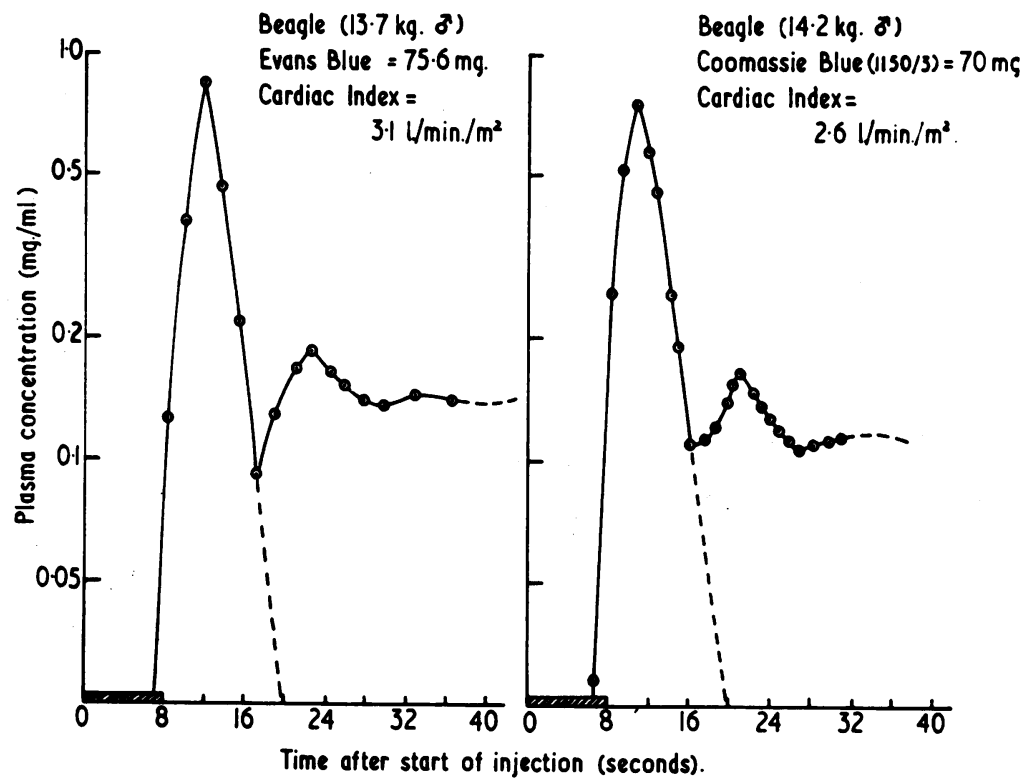

Fig. 4.-Examples of dye dilution curves obtained in dogs (beagles) using Evans Blue and Coomassie Blue.

\section{DisCUSSION}

The physical and chemical properties of the azo dye, Coomassie Blue, make it theoretically a most suitable dye for methods employing indicator dilution techniques, and the present study has confirmed its promising potential for biological use. The rate of in vivo degradation and excretion of the dye are optimal in that they are sufficiently slow to allow accurate determinations of the plasma concentration and yet at the same time rapid enough to cause only transient skin discoloration. The low toxicity and ease of extraction of the dye from the plasma protein, to which it is bound, are real advantages over Evans Blue $(T-1824)$. Aqueous extracts of the dye from the 
plasma have identical absorption spectra with that of the uninjected dye, indicating that the dye behaves homogeneously after injection. This is supported by chromatographic evidence and is in contrast to some samples of Evans Blue. Cooley (1954) found appreciable amounts of rapidly metabolized impurities in standard solutions of the latter dye that may seriously affect quantitative estimations in vivo. In contrast to the recently proposed tricarbocyanine dyes "Cardio-Green" (Fox et al., 1957) and "Rie 1743" (Kramer and Ziegenrücker, 1957), Coomassie Blue is stable in aqueous solution and not light sensitive. This is of particular importance in considering the dye for practical clinical use.

Several dyes, having a very rapid clearance from the blood, have recently been proposed as suitable for serial determinations of cardiac output. Amongst these are Indigo Carmine (Lacy et al., 1955), Bromsulphalein (Wassen, 1956; Mellette et al., 1958) and three inter-related blue triphenylmethane dyes (Davis et al., 1958). These dyes are, however, only suitable for use, where estimations of blood dye concentrations are made on samples withdrawn from an artery, as a significant difference between arterial and venous dye content results from the rapid rates of diffusion and hepatic clearance that characterize these dyes. Thus venous blood samples do not permit standardization of the response of an ear-piece detector, a serious practical limitation.

With regard to Coomassie Blue, the present animal studies demonstrate that the dye is initially confined entirely to the intravascular space, a factor of prime importance in the in vivo measurement of blood flow and the estimation of plasma volume by dye space. The clearance of Coomassie Blue from the plasma is neither too slow to limit the frequency of successive determinations, nor too rapid to introduce an appreciable error in the calculation of blood flow and volume. The absence of skin staining is a great advantage when considering clinical use of the dye, especially if repeated observations are required.

\section{SUMMARY}

The dye, Coomassie Blue, has been found to have properties suitable for its use with indicator dilution techniques.

It is stable in aqueous solution, non-toxic, and does not cause staining of the skin.

The concentration of Coomassie Blue in plasma may be readily and accurately determined.

The dye is localized in the intravascular space by binding to the plasma proteins, from which it is cleared at a rate intermediate between that of the highly persistent Evans Blue and that of the rapidly cleared Indigo Carmine.

We are indebted to Drs. F. L. Rose, F.R.S., J. Raventos, W. G. M. Jones, W. A. M. Duncan, A. Spinks, A. L. Walpole, J. Madinaveitia, G. E. Paget, Mr. K. Howarth, and Miss N. Leech of Imperial Chemical Industries for advice and assistance in various phases of this work, and to Professor J. McMichael, F.R.S., and Dr. J. Shillingford of the Postgraduate Medical School for their interest and encouragement.

\section{REFERENCES}

Clausen, D. F., and Lifson, N. (1956). Proc. Soc. exp. Biol., 91, 11.

Cooley, G. (1954). J. Physiol., 123, 16.

Davis, H. A., Al-Fadley, W., and Gibson, L. H. (1958). Proc. Soc. exp. Biol., 98, 345.

Dawson, A. B., Evans, H. M., and Whipple, G. H. (1920). Amer. J. Physiol., 51, 232.

Fouts, J. R., Kamm, J. J., and Brodie, B. B. (1957). J. Pharmacol., 120, 291.

Fox, I. J., Brooker, L. G. S., Heseltine, D. W., Essex, H. E., and Wood, E. H. (1957). Proc. Mayo Clinic, 32, 478.

Hamilton, W. F., Riley, R. L., Attyah, A. M., Cournand, A., Fowell, D. M., Himmelstein, A., Noble, R. P., Remington, J. W., Richards, D. W., Wheeler, N. C., and Witham, A. C. (1948). Amer. J. Physiol., 153, 309.

Kramer, K., and Ziegenrücker, G. (1957). Klin. Wschr., 35, 468.

Lacy, W. W., Ugaz, C., and Newman, E. V. (1955). Circulat. Res., 3, 570.

Mellette, H., Booth, R. W., Ryan, J. M., and Rieser, G. F. (1958). J. Lab. clin. Med., 51, 441.

Taylor, S. H., and Shillingford, J. P. (1959). Brit. Heart J., 21, 497.

Wassen, A. (1956). Scand. J. clin. Lab. Invest., 8, 189.

Werkö, L., Lagerlöf, H., Bucht, H., Wehle, B., and Holmgren, A. (1949). Scand. J. clin. Lab. Invest., 1, 109. 